\title{
Caracterização molecular de Prosopis juliflora (Sw.) DC. por meio de marcadores moleculares e índices de similaridade genética
}

\author{
Messulan Rodrigues Meira ${ }^{1,4 *}$ \\ Luiz Henrique Tolentino Santos ${ }^{2,4}$ \\ Quirlian Queite Araújo Anjos 2,4 \\ Brenda Emilly Ferreira dos Santos ${ }^{4}$ \\ Leonardo de Sousa Guimarães ${ }^{4}$ \\ Carlos Bernard Moreno Cerqueira Silva ${ }^{1,2,3,4}$

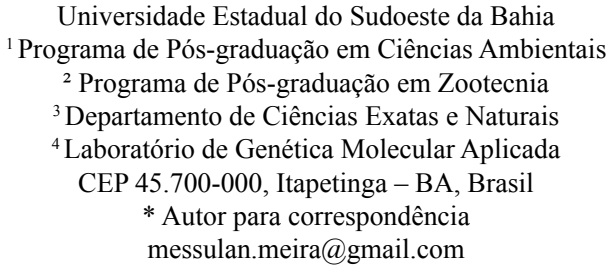

Submetido em $27 / 11 / 2019$

Aceito para publicação em 05/02/2020

\section{Resumo}

Algaroba, Prosopis juliflora (Sx.) DC., é uma espécie arbórea adaptada no Brasil com valor alimentício animal e ambiental para reflorestamento. Porém pouco se sabe sobre sua diversidade genético-molecular. Portanto objetivou-se estudar diferentes índices de similaridade a partir de caracterizações genéticas da algaroba obtidas por meio dos marcadores ISSR e RGA em indivíduos naturalizados no sudoeste da Bahia. Folhas jovens de 36 indivíduos foram coletadas no município de Itapetinga, Bahia. O DNA foi extraído pelo método SDS 10\% e quantificado pela razão de absorbância A260/A230 e A 260/A280 nm. Dez pares de RGA e 23 iniciadores ISSR foram utilizados para a reação de PCR, cujas reações foram submetidas à eletroforese em gel de agarose a $2 \%$ por $2 \mathrm{~h}$. O resultado da genotipagem (matriz binária) foi utilizado para cálculo dos índices de similaridade de Jaccard, Simple Matching e Sorensen Dice. Por fim, foram realizados os agrupamentos UPGMA, otimização de Tocher e PCA. Foram observados 205 e 68 marcas polimórficas, com heterozigosidade esperada de 0,28 e 0,21 ; informação polimórfica de $91,71 \%$ e $0,17 \%$ e distância genética de 8,0 e 8,53 para ISSR e RGA, respectivamente. Essas informações contribuem para o entendimento da distribuição e adaptação da espécie em áreas reflorestadas.

Palavras-chave: Algaroba; Coeficientes de similaridade; Diversidade; Recurso genético 


\section{Abstract}

Molecular characterization of Prosopis juliflora SW. DC. through molecular markers and genetic similarity indices. Prosopis juliflora (Sx.) DC., commonly known as algarroba, is an adapted tree species in Brazil with animal food value and environmental value in reforestation. However, little is known about its molecular genetic diversity. Therefore, the aim of our study was to use different similarity measures based on the genetic characterization of algarroba obtained through ISSR and RGA markers in naturalized individuals in southwestern Bahia. Young leaves of 36 algarroba individuals were collected in the municipality of Itapetinga, Bahia. DNA was extracted by the $10 \%$ SDS protocol and quantified by the absorbance ratio A260/A230 and A260/A280 nm. Ten pairs of RGA and 23 primers of ISSR were used for PCR, and the amplified products were electrophoresed on $2 \%$ agarose gels for $2 \mathrm{~h}$. The genotyping results (binary matrix) were used to calculate the Jaccard, Simple Matching and Sorensen Dice similarity coefficients. Finally the UPGMA clustering, Tocher optimization and PCA were performed. We observed for ISSR and RGA 205 and 68 marks, respectively, with expected heterozygosity of 0.28 and 0.21 ; polymorphic information content was 91.71 and $0.17 \%$ and genetic distance 8.0 and 8.53 , respectively. These findings contribute to our understanding of the wide distribution and adaptation of this species in reforested areas.

Key words: Algarroba; Diversity; Genetic resources; Similarity coefficients

\section{Introdução}

A Prosopis juliflora ( $\mathrm{Sw}$ ) D.C. é uma espécie arbórea, xerófita, pertencente à família Leguminosae e subfamília Mimosoideae (PEGADO et al., 2006), sendo conhecida popularmente como algaroba. De origem africana, é bem adaptada ao Brasil, facilmente encontrada em beira de estradas e áreas de pastagens. No nordeste brasileiro é considerada como árvore de uso múltiplo. Devido à densidade de suas populações, é amplamente utilizada em reflorestamento de áreas degradadas (RODRIGUES et al., 2013). E em função da abundância e palatabilidade dos frutos, também passou a ser apreciada como fonte de alimento para grandes ruminantes, muares e equinos em estações secas (MEDEIROS et al., 2012).

Esse atributo é devido aos frutos apresentarem cerca de 8 a $13 \%$ de proteína e digestibilidade superior a $74 \%$, com $4.501 \mathrm{kcal}^{\mathrm{kg}} \mathrm{kg}^{-1}$ de energia bruta em sua composição. Por isso, atualmente, seus frutos são recomendados para a substituição do milho e de outras culturas irrigadas utilizadas como componente adicional à dieta animal, os quais têm elevado o custo de produção animal (MEDEIROS et al., 2012).

Diante dos atributos apresentados pela espécie, pouco se conhece acerca da estrutura genética quanto à distribuição, grau de heterozigosidade e índice de locos polimórficos em populações plantadas no sudoeste baiano, sendo essa informação muito importante para subsidiar futuros planos de manejo da espécie, como, por exemplo, aumentar a variabilidade genética das populações a fim de atrair agentes polinizadores. Para estudos dessa natureza, existem vários tipos de marcadores moleculares. Dentre esses, destacam-se dois dominantes, o marcador ISSR (Inter Simple Sequence Repeat) e o RGA (Resistance Genes Analogs). Ambos marcadores dispensam conhecimento prévio do genoma. Por isso são recomendados para a caracterização molecular de espécies exóticas como a algaroba, e as informações obtidas com seus descritores genéticos poderão subsidiar futuros programa de melhoramento (SEKHAWAL et al., 2015).

O primeiro marcador, o ISSR, foi inspirado nos microssatélites e no RAPD. Este tem a capacidade de identificar fragmentos no DNA de poucos pares de base repetidos em Tadem, o que confere alto polimorfismo para estudos de diversidade genética (REDDY et al., 2002), além de possuir custo acessível e boa reprodutibilidade (ZOLET et al., 2017). O segundo marcador, o RGA, é constituído por regiões análogas aos genes de resistência, com características polimórficas semelhantes ao ISSR. Porém esse marcador revela polimorfismo de indivíduos com genes de resistência a algum fator adverso, o que pode explicar a boa disseminação e adaptação da planta em regiões áridas diferentes daquelas regiões de origem (SEKHAWAL et al., 2015). 
Além dos marcadores moleculares, identificar o índice de similaridade genética que melhor responde aos estudos genéticos e moleculares de cada espécie é muito importante. Os coeficientes de similaridade são utilizados para estudos de dados binários, os quais se baseiam na comparação do número de atributos comuns para cada par de objetos e o número total de atributos envolvidos. Tais coeficientes podem ser facilmente transformados em semelhança ou diferença entre os pares de genótipos. Os índices de similaridade mais estudados são o de Jaccard, Sorensen Dice e Simple Matching (BORÉM; CAIXETA, 2009). Esses três possuem características em comum por considerar a ausência conjunta de dados obtidos a partir de uma matriz binária. Entretanto, sua robustez pode variar em relação à importância dada a sua ausência e ou presença, ou até mesmo a sua não coincidência, a qual pode variar de uma espécie para outra (DUARTE et al., 1999). Com isso, objetivou-se estudar diferentes índices de similaridade a partir da caracterização genética de $P$. juliflora obtida por meio de ISSR e RGA em indivíduos naturalizados no sudoeste da Bahia.

\section{Material e Métodos}

O material vegetal procedeu-se de folhas jovens de 36 indivíduos de $P$. juliflora (algaroba) coletados no município de Itapetinga, Bahia, sob as coordenadas geográficas: Latitude $15^{\circ} 14^{\prime} 57,8^{\prime \prime}$ e Longitude $40^{\circ} 13$ ' $53,4^{\prime \prime} \mathrm{W}$, localizado na mesorregião sudoeste. O material botânico foi herborizado no Herbário da Universidade Estadual de Santa Cruz, sob o número de registro RG-14435, e registrado no SisGen (Sistema Nacional de Gestão do Patrimônio Genético e Conhecimento Tradicional Associado), sob o número de registro AFF0E34. Após a coleta, o material foi acondicionado em caixa de isopor com gelo e encaminhado ao laboratório para extração de DNA genômico.

Posteriormente à coleta das folhas jovens, o estudo foi realizado no Laboratório de Genética Molecular Aplicada (LGMA), da Universidade Estadual do Sudoeste da Bahia (UESB), no período de junho de 2017 a julho de 2019.
Para a extração do DNA genômico, utilizouse o protocolo SDS (Dodecil Sulfato de Sódil) 10\% estabelecido por Sunnucks e Hales (1996). Esta etapa procedeu-se da maceração de $0,2 \mathrm{~g}$ de folhas jovens em $3 \mathrm{~mL}$ de tampão SDS $10 \%$ pré-aquecido a $60^{\circ} \mathrm{C}$. $\mathrm{Na}$ sequência o material foi aquecido em banho-Maria por $3 \mathrm{~h}$ a $55-60^{\circ} \mathrm{C}$, com homogeneização a cada 20 min. Os microtubos foram resfriados em temperatura ambiente e centrifugação a $12.000 \mathrm{RPM}$ por $10 \mathrm{~min}$ a $15^{\circ} \mathrm{C}$. Após essa etapa, transferiu-se o sobrenadante e acrescentaram-se $700 \mu \mathrm{L}$ de isopropanol gelado. O material foi homogeneizado lentamente e o processo de centrifugação, repetido. No sobrenadante final, realizouse duas lavagens, uma com $800 \mu \mathrm{L}$ de etanol $70 \%$ e outra com $800 \mu \mathrm{L}$ a $95 \%$, subsequentemente. O pellet foi mantido overnight para secagem e ressuspendido em $60 \mu 1$ de tampão para ressuspensão (Tris-EDTA 0,1X e $\mathrm{H}_{2} \mathrm{O}$ ultra pura q.s.p.). A quantificação e a pureza do DNA genômico foram estimados em espectrofotômetro BioDrop $\mu$ LITE (Whitehead Scientific) na razão de A260/A230 e A260/A280 nm de absorbância. Subsequentemente, as amostras de DNA genômico foram padronizadas em $50 \mathrm{ng} . \mu \mathrm{L}^{-1}$.

A amplificação em cadeia de polimerase (PCR) do material foi realizada em termocliclador Veriti 96 Well Thermal Cycler (Applied Biosystems ${ }^{\circledR}$ ). Utilizaram-se 10 pares de iniciadores de Genes análogos de resistência RGA: S1-NBSr1; S1-As2; S1-As3; NBsf1-NBrf1; RGA1f-RGA2r; RGA1fRGA5r; RGA1f-RGA6r; RGA1f-RGA8r; As1-As2; As1-As 3 em 20 acessos e 23 iniciadores ISSR: DIGA3'G; DICA3'RG; DICA3'YG; DIGA3'C; DIGA3'RC; DIGA3'T; TRICAC3'RC; TRICAC3'YC; TRICAC5'CY; TRICAG3'RC; TRIGTG3'YC; TRITGT3'YC; TRIAAC3'RC; TRIAAG3'RC; TRIACA3'RC; TRIAGA3'RC; TRITGG'RC; TRICGA3'RC; TRICGC3'RC; TRIGAC3'RC; TRIGCA3'RC; TRIGCC3'RC e TRIGGA3'RC em 16 acessos diferentes, respectivamente.

A reação de PCR para os iniciadores RGA foi preparada a partir de $8 \mu \mathrm{L}$ de DNA a 2 ng, 1,7 de tampão para PCR 10X (20 mM Tris-HCl [pH 8,4] e $50 \mathrm{mM}$ de $\mathrm{KCl}), 1,0 \mu \mathrm{L} \mathrm{MgCl}_{2}, 1 \mu \mathrm{L}$ de dNTP mix $2,5 \mathrm{mM}, 0,11 \mu \mathrm{L}$ de Taq DNA polimerase Taq e 2,19 $\mu \mathrm{L}$ de água Milli-Q 
e $1 \mu \mathrm{L}$ de cada iniciador, totalizando $16 \mu \mathrm{L}$ de volume final. A configuração adotada para as reações de PCR foi: desnaturação inicial a $95^{\circ} \mathrm{C}$ durante $1 \mathrm{~min}$, seguido por 35 ciclos de $95^{\circ} \mathrm{C}$ por $40 \mathrm{~s}$ para desnaturação, $37^{\circ} \mathrm{C}$ por $60 \mathrm{~s}$ para anelamento e $72^{\circ} \mathrm{C}$ por $1 \mathrm{~min}$ para extensão e finalizado com mais 5 min., para extensão final a $72^{\circ} \mathrm{C}$.

A reação de PCR para os iniciadores ISSR foi preparada a partir de $8 \mu \mathrm{L}$ de DNA a $2 \mathrm{ng}, 1,7 \mu \mathrm{L}$ de tampão para PCR 10X (20 mM Tris- $\mathrm{HCl}[\mathrm{pH} 8,4]$ e 50 $\mathrm{mM}$ de $\mathrm{KCl}), 1,0 \mu \mathrm{L}$ de $\mathrm{MgCl}_{2}, 1,0 \mu \mathrm{L}$ de dNTP mix 2,5 $\mathrm{mM}, 0,11$ de Taq DNA polimerase (LGC biotecnologia) e 3,19 $\mu \mathrm{L}$ de água Milli-Q e 1,0 $\mu \mathrm{L}$ de iniciador, totalizando $16 \mu \mathrm{L}$ de volume final. Para a reação de amplificação foi adotado o programa de amplificação iniciado com $95^{\circ} \mathrm{C}$ por $5 \mathrm{~min}$; seguido de 34 ciclos $\left(94^{\circ} \mathrm{C}\right.$ por $50 \mathrm{~s} ; 48^{\circ} \mathrm{C}$ por $60 \mathrm{~s} ; 72^{\circ} \mathrm{C}$ por $60 \mathrm{~s}$ ) e uma extensão final a $72^{\circ} \mathrm{C}$ de $5 \mathrm{~min}$.

Após a obtenção do produto de amplificação, alíquotas de $6 \mu \mathrm{l}$ foram submetidas à eletroforese em gel de agarose a $2 \%(\mathrm{~m} / \mathrm{v})$ durante $2 \mathrm{~h}$ com tampão de corrida TBE $0,5 \mathrm{x}$ em corrente elétrica de $120 \mathrm{~V}$ durante $120 \mathrm{~min}$. As amostras foram coradas com $0,2 \%(\mathrm{~m} / \mathrm{v}) \mathrm{de}$ Gel Red (Invitrogen) e sua concentração foi comparada com alíquotas conhecida de fago de DNA lambda $(\lambda)$ (Invitrogen). Após corrida de eletroforese, os géis foram visualizados em transluminador sob luz ultravioleta e fotodocumentados em câmera Kodak.

Os dados obtidos foram genotipados no Excel em matriz binária de presença (1) e ausência (0) de bandas. Obtida a matriz binária, prosseguiram-se com as análises genético-moleculares, onde calculou o PIC conforme a fórmula proposta por Botstein et al. (1980):

$$
P I C=1-\sum_{i=1}^{n} p_{i}^{2}-\sum_{i=1}^{n} \sum_{j=1+1}^{n} 2 p_{i}^{2} p_{j}^{2}
$$

Para as demais etapas, utilizaram-se três coeficientes, sendo Simple Matching Jaccard e SorensenDice, respectivamente (JACCARD, 1908; SOKAL; ROHLF, 1962), representados pelas equações:

$$
S M=a+\frac{b}{a}+b+c+a
$$

$$
\begin{aligned}
J & =\frac{a}{a+b+c} \\
S D & =\frac{a}{2 a+b+c},
\end{aligned}
$$

em que todos os três índices apresentam o mesmo intervalo de ocorrência, 0,1 .

Os resultados apresentados por cada índice foram submetidos ao método de agrupamento UPGMA (Unweighted Pair - Group Method Using Arithmetic Averages) (SNEATH; SOKAL, 1973). Nesse método utilizou-se a média aritmética das medidas de distância, sendo construídas, assim, a estrutura do dendrograma pelos indivíduos de maior similaridade e a distância entre um indivíduo $k$ e um grupo formado, fornecida pela equação:

$$
d k=\frac{d_{i k+d_{j k}}}{2}
$$

onde $d_{(i j) k}$ foi obtida pela média dos conjuntos das distâncias dos pares de indivíduos (i e k) e (j e k). A representação hierárquica dos dados foi obtida adotando a rotina SAHN (sequencial, aglomerative, hierarchical, no overlapping). Para essa etapa, adotou-se a similaridade proposta na distância genética de Nei (1978), conforme a equação:

$$
S i i^{\prime}=\frac{2 a}{b+c}
$$

onde i e i' são dois indivíduos com as presenças comuns $(1-1)$, b e c, presenças não comuns (1 - 0 e 0 - 1), respectivamente.

Obtidas as matrizes de dissimilaridade, realizouse o método de agrupamento de otimização de Tocher. E, para melhor atribuição dos parâmetros analisados, os dados também foram submetidos à Análise da Componente Principal (ACP). Os resultados obtidos com o índice de otimização de Tocher foram comparados com os resultados apresentados por cada dendrograma de acordo seus respectivos coeficientes e pela análise discriminante da componente principal, conforme preconizado por Cruz et al. (2011). As análises estatísticas foram viabilizadas com o auxílio do Software NTSYs pc v. 2.11 (ROHLF, 2000). 


\section{Resultados}

Os iniciadores RGA apresentaram 68 marcas polimórficas com média de 5,7 por iniciador, a heterozigosidade média esperada de 0,21 e PIC de 0,17\%. Já os iniciadores ISSR apresentaram 205 marcas com média de 8,95 por iniciador, com heterozigosidade média esperada de 0,28 e PIC de 91,71\%, respectivamente.

Quanto aos coeficientes de similaridade, Simple Matching (SM), Jaccard (JC) e Sorensen-Dice (SD), as matrizes binárias obtidas a partir da genotipagem dos acessos para os dois marcadores apresentaram valores de similaridade próximos entre si. Sendo maiores os valores obtidos para os coeficientes SM $(8,53$ e 8,0$)$ e SD $(7,83$ e 8,13 ), para os acessos 2 e 3 e os menores coeficientes foram observados para JC $(6,43$ e 6,85$)$, para o acesso 3 para os marcadores RGA e ISSR, respectivamente (Tabela 1).
A aplicação dos três coeficientes de similaridade na análise de agrupamento UPGMA, para os dois marcadores, separou os acessos em dois grupos distintos. Os acessos 12, 13 e 14 formam um grupo isolado para o RGA e os acessos 1, 2, 3 e 4 foram separados dos demais para o ISSR (Tabela 2).

As distâncias genéticas geradas pelos coeficientes foram corroboradas pelos dendrogramas, apresentando o coeficiente de Sorensen-Dice (SD) como o de maior correlação. Na genotipagem apresentada pelo RGA, o coeficiente de Jaccard (JC) apresentou agrupamento semelhante ao de Sorensen-Dice (SD), com corte de distância em 1,0, correspondendo a 93 e $87 \%$ do valor do índice de similaridade. Para a genotipagem apresentada pelo ISSR, o índice de Simple Maching (SM) foi semelhante ao Sorensen-Dice (SD). Esses dois coeficientes apresentaram os melhores valores, com corte em 4,0 e 4,5, representando $88 \%$ de correção de

TABELA 1: Distâncias dos pares de acessos de Prosopis juliflora gerados a partir de matrizes de similaridade por meio de marcadores RGA e ISSR.

\begin{tabular}{lcccc}
\hline \multirow{2}{*}{ Coeficientes } & \multicolumn{2}{c}{ RGA } & ISSR \\
\cline { 2 - 5 } & Distância & Acesso & Distância & Acesso \\
\hline \multirow{2}{*}{ Simple Matching - SM } & 8,53 & 2 & 8,00 & 2 \\
& 8,23 & 4 & 8,00 & 3 \\
\hline \multirow{2}{*}{ Jaccard - JC } & 6,43 & 2 & 6,85 & 3 \\
& 5,86 & 4 & 6,80 & 2 \\
\hline \multirow{2}{*}{ Sorensen-Dice-SD } & 7,83 & 2 & 8,13 & 3 \\
& 7,39 & 4 & 8,09 & 2 \\
\hline
\end{tabular}

TABELA 2: Agrupamento dos acessos de Prosopis juliflora pelo método UPGMA por meio dos coeficientes de SorensenDice (SD), Jaccard (JC) e Simple Matching (SM), obtidos por genotipagem por meio de iniciadores RGA e ISSR.

\begin{tabular}{|c|c|c|c|c|}
\hline \multirow{2}{*}{ Marcadores } & \multirow{2}{*}{ Grupos } & \multicolumn{3}{|c|}{ Índice de similaridade } \\
\hline & & $\mathrm{JC}$ & SD & SM \\
\hline \multirow[b]{2}{*}{ RGA } & I & 14 & 14 & $12,13,14$ \\
\hline & II & Todos, exceto 14 & Todos, exceto 14 & $\begin{array}{c}\text { Todos, exceto } \\
12,13,14 \\
\end{array}$ \\
\hline \multirow{3}{*}{ ISSR } & $\mathbf{I}$ & $1,2,3,4$ & $1,2,3,4$ & $1,2,3,4$ \\
\hline & II & $\begin{array}{c}5,6,7,8,9,10,11,12 \\
13,14,15,16\end{array}$ & $\begin{array}{c}5,6,7,8,9,10,11 \\
12,13,14,15,16\end{array}$ & $\begin{array}{c}5,6,7,8,9,10,11,12,13,14 \\
15,16\end{array}$ \\
\hline & & \multicolumn{3}{|c|}{ Coeficientes de Similaridade } \\
\hline RGA & & 0,93 & 0,87 & 0,94 \\
\hline ISSR & & 0,51 & 0,88 & 0,88 \\
\hline
\end{tabular}


TABELA 3: Distâncias genéticas dos acessos de Prosopis juliflora pelo índice de otimização de Tocher, a partir dos três coeficientes de similaridade obtidos por meio dos marcadores RGA e ISSR.

\begin{tabular}{cc|ccc|ccc}
\hline \multirow{2}{*}{ Grupo } & \multirow{3}{*}{ Marcador } & \multicolumn{4}{|c}{ Distâncias Genéticas } & \multicolumn{3}{c}{ Média } \\
\cline { 3 - 8 } & & JC & SD & SM & JC & SD & SM \\
\hline 1 & RGA & 2,53 & 3,70 & 5,95 & 0,127 & 0,185 & 0,298 \\
1 & ISSR & 4,04 & 5,62 & 0,48 & 0,288 & 0,41 & 0,69 \\
2 & & 3,70 & 5,39 & - & 1,850 & 2,695 & - \\
\hline
\end{tabular}

JC: Jaccard; SD: Sorensen-Dice; SM: Simple Matching.

similaridade. Ao passo que o Jaccard (JC) apresentou a menor correlação, com corte em 3,0, correspondendo a $51 \%$ do coeficiente (Tabela 2 ).

A melhor similaridade entre os três coeficientes estudados, evidenciando a pequena diferença genética entre os acessos, foi confirmada pelo índice de otimização de Tocher, em que a genotipagem com o iniciador RGA e o teste de otimização de Tocher agruparam todos os acessos em único grupo (Tabela 3).

Para a genotipagem com ISSR, esse índice apresentou formação de dois grupos para os coeficientes de Jaccard (JC) e Sorensen-Dice (SD). Ao passo que o coeficiente de Simple Matching (SM) agrupou todos os indivíduos em apenas um grupo (Tabela 4).

TABELA 4: Agrupamentos de acessos de Prosopis juliflora pelo índice de otimização de Tocher, a partir de três coeficientes de similaridade obtidos por meio de marcadores ISSR.

\begin{tabular}{cccc}
\hline & \multicolumn{2}{c}{ Coeficientes de similaridade } \\
\hline Grupos & JC & SD & SM \\
\hline I & $1,2,3,4,5,6$ & $1,2,3,4,5,6$ & Todos os acessos \\
\hline II & $7,8,11,12,13,14,15,16$ & $7,8,11,12,13,14,15,16$ & 9 e 10 \\
\hline
\end{tabular}

* JC: coeficiente de Jaccard; SD: coeficiente de Sorensen-Dice e SM: coeficiente Simple Matching.

FIGURA 1: Representação bidimensional da Análise de Componente Principal (PCA) de 16 e 20 acessos de Prosopis juliflora a partir dos marcadores moleculares RGA e ISSR.

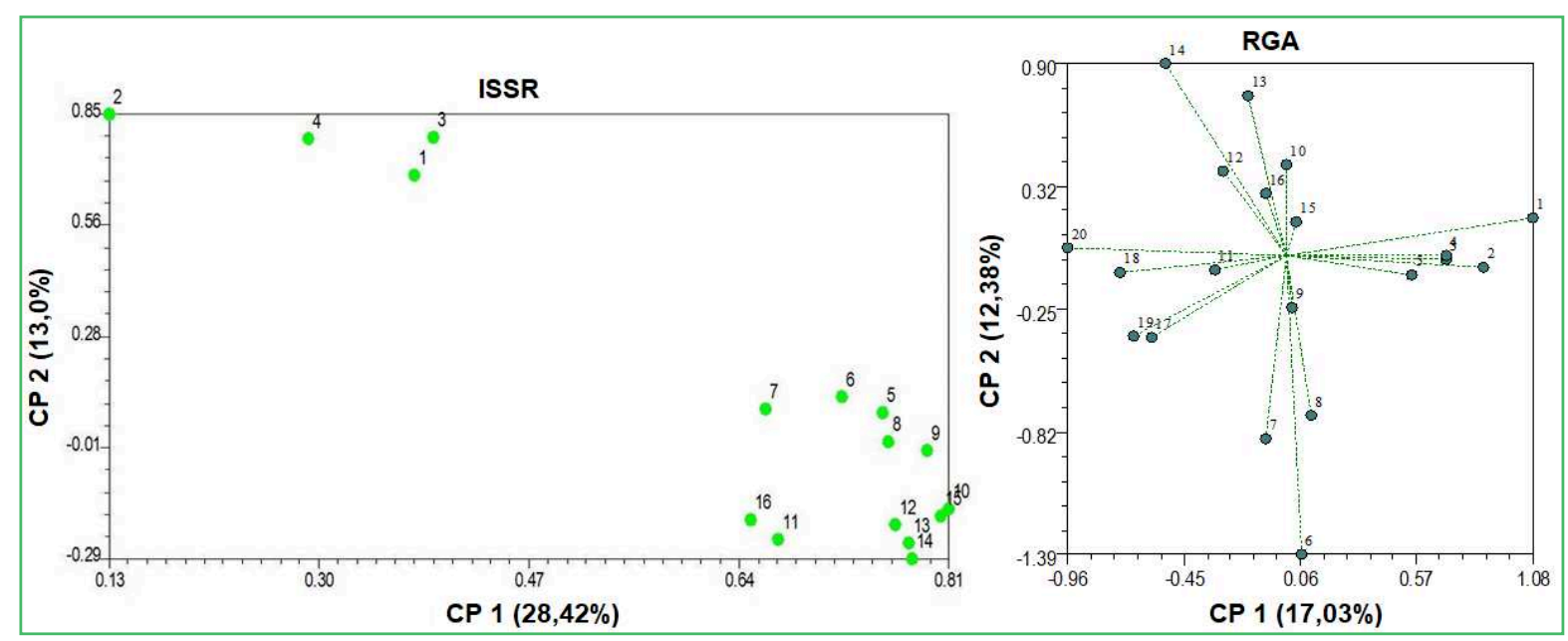


Ao comparar a Análise da Componente Principal com os agrupamentos obtidos pelo agrupamento UPGMA, observou-se que os acessos genotipados com ISSR também dividiram os acessos em dois grupos, cujos componentes contribuíram com $41,42 \%$. Onde o primeiro componente explicou $28,42 \%$ da variância total, e o segundo componente explicou $13 \%$ de todas as variáveis obtidas. Todos os acessos foram agrupados pelo primeiro e terceiro quadrante (Figura 1; Tabela 2).

Os acessos genotipados com RGA apresentaram distribuição espacial homogênea em todos os quadrantes da PCA, não formando grupos distintos. Os autovalores acumulados dos eixos contribuíram com apenas 29,41\%. O primeiro componente para essa análise discriminante contribuiu com $17,03 \%$ para explicar a variância dos acessos e a segundo componente principal explicou 12,38\% (Figura 1).

\section{Discussão}

Mesmo que o ISSR tenha apresentado valores polimórficos e de PIC superiores ao RGA, ambos os resultados mostraram a eficiência desses marcadores para estudo de diversidade genética. O polimorfismo apresentado é considerado grande o suficiente para estudo dessa natureza, uma vez que cada marcador tem a sua especificidade (ZOLET et al., 2017). Enquanto o ISSR detecta pequenos fragmentos de DNA com sequências de nucleotídeos de tamanho variado ao longo do genoma comum a todos os indivíduos da espécie (COSTA et al., 2015), o RGA, ainda que apresente a mesma função molecular, de caracterização genética, tem o atributo de identificar regiões alvo conservadas de sequências nucleotídicas ricas em leucina (LRR - Leucine Rich Repeats); essas regiões são sítios de ligação de nucleotídeo (NBS - Nucleotide Binding Sites) a proteínas quinase. Os domínios NBSLRR nas plantas possuem a função de se associar a genes de resistência em resposta à hipersensibilidade. O domínio LRR é o responsável pelo reconhecimento primário de possíveis patógenos (JONES; DANGL, 2006), atuando, assim, como guarda da maquinaria celular (SEKHWAL et al., 2015).
Embora os coeficientes de similaridade tenham apresentado diferença entre si e distribuído os acessos em grupos distintos nos dendrogramas, mantiveram o mesmo padrão de agrupamento dos acessos independemente dos seus valores. Isso se deve ao fato de o algoritmo UPGMA não considerar a estrutura de subdivisão do grupo, atribuindo peso igual para todos os acessos, ainda que o menor índice de similaridade entre eles seja utilizado como critério de inclusão. Portanto, esse fato evidencia que os acessos são oriundos da mesma matriz genética e partilham os mesmos caracteres evolutivos (NEY, 1978; MEYER, 2002). Essa observação é esclarecida pelo índice de otimização de Tocher a partir dos níveis de fusão, em que independentemente do coeficiente aplicado, os acessos pertencem à mesma população, não apresentando distância genética suficiente que justificasse a separação dos acessos em mais de um grupo (Tabela 4) (CRUZ et al., 2011; ARAÚJO et al., 2017).

Já a separação dos genótipos apresentada pela PCA para o marcador ISSR corroborou os agrupamentos apresentados pelos dendrogramas para os dois marcadores (Figura 1; Tabela 2). Entretanto, a distribuição homogênea dos genótipos para o marcador RGA corroborou os resultados apresentados tanto pela otimização de Tocher quando pelo coeficiente de similaridade de coincidência simples (SM) apresentado pelo ISSR, que considerou os acessos pertencentes à mesma população, em virtude das pequenas distâncias genéticas de 0,48 entre os índices (Tabela 3) (ARAÚJO et al., 2017).

Para que a ACP explique a distribuição espacial dos genótipos, é necessário que os autovalores acumulados dos componentes principais tenham contribuído ao menos com $70 \%$ da variação total presente em cada acesso (HONGYU et al., 2015). Portanto, não se pode afirmar a separação dos acessos em duas populações. Sendo possível, então, inferir que os acessos pertencem à mesma população, uma vez que a contribuição de cada eixo apresentou valores inferiores ao preconizado pela literatura acima citada $(\mathrm{CP} 1=28,42 \%$ e CP2 $=13 \%)$. (Tabelas 3 e 4; Figura 1). Todavia, este estudo é o primeiro registro de 
caracterização genética por meio de RGA. Ainda que também tenha apresentado baixa contribuição para cada componente principal ( $\mathrm{CP} 1=17,03 \%$ e CP $2=12,38 \%)$, contribuiu para o entendimento da distribuição espacial dos acessos pela análise discriminante.

Informações como essas são muito importantes para o entendimento da ampla distribuição e adaptação da espécie em ambientes áridos e semiáridos inóspito para agricultura e outro tipo de vegetação em determinadas estações do ano, sendo possível inferir que os possíveis genes expressos pela algaroba como possibilidade de resistência a condições adversas mostram que os indivíduos estão bem adaptados para a área de ocorrência onde a população foi naturalizada (RODRIGUES et al., 2013).

A baixa variabilidade genética apresentada pela espécie pode ser explicada pela boa reprodução vegetativa, a qual confere à espécie a característica de potencial invasor por ocupar rapidamente grandes áreas (PEGADO et al., 2006). Não obstante, a falta de conhecimento quanto ao tamanho efetivo de suas populações também pode explicar essa questão. Embora a espécie seja alógama, devido ao fato de formar povoamentos densos, pode ocorrer cruzamento entre indivíduos aparentados, contribuindo dessa forma para elevar o índice de endogamia com consequente redução do fluxo gênico (PIRES; KAGEYAMA, 1985; HARTL; CLARK, 2010).

Contudo, o conjunto desses fatores pode ter contribuído para manter a replicação dos genótipos desta espécie desde a sua introdução no Brasil em meados da década de 1940 (BURNNET, 2017), de forma que todas as subpopulações existentes atualmente no Brasil são progênies dos primeiros indivíduos.

Informações como essas asseguram seu uso para construção civil e energia sem comprometer seus recursos genéticos. Dessa forma, é importante que as demais populações naturalizadas da algaroba tenham sua caracterização genética registrada, contribuindo, assim, para o mapeamento da espécie e melhor direcionamento de seus usos sob regime de manejo sem trazer maiores prejuízos ambientais (ANDRADE et al., 2010; CUNHA; SILVA, 2012).
Os resultados mostraram que os acessos de algaroba apresentam baixa variabilidade genética. Sendo o coeficiente de coincidência simples o que apresenta maior distância genética, e o Sorensen-Dice, a melhor correlação. E os marcadores RGA e ISSR mostraram-se eficientes para a caracterização genética de algaroba. Contudo, informações como essas são muito importantes para o entendimento da ampla distribuição e adaptação da espécie em áreas reflorestadas.

\section{Agradecimentos}

Aos órgãos de fomento à pesquisa: CNPq, CAPES pela concessão das bolsas de doutoramentos, à FAPESB pelo apoio financeiro referente ao Projeto de Intra PIE 0014/2016 e aos Programa de Pós-Graduação em Zootecnia e Ciências Ambientais da UESB - Campus Itapetinga, pela possibilidade da pesquisa e estrutura física.

\section{Referências}

ANDRADE, L. A.; FABRICANTE, J. R.; OLIVEIRA, F. X. Impactos da invasão de Prosopis juliflora (Sw.) DC. (Fabaceae) sobre o estrato arbustivo-arbóreo em áreas de Caatinga no estado da Paraíba, Brasil. Acta Scientiarum Biological Sciences, Maringá, v. 32, 3, p. 249-255, 2010.

ARAÚJO, L. B. R.; NETO, A. M. B.; GODIM, G. M. C.; PIRES, K. R. A.; BERTINI, C. H. C. M. Diversidade genética em famílias de meios-irmãos de pinhão manso. Enciclopédia Biosfera, Goiânia, v. 14, n. 25 , p. $452-465,2017$.

BORÉM, A.; CAIXETA, E. T. (Ed.). Marcadores moleculares. 2. ed. Viçosa: Universidade Federal de Viçosa; Brasília: Embrapa Café, 2009. 532 p.

BOTSTEIN, D.; WHITE, R. L.; SKOLNICK, M.; DAVIS, R. W. Construction of a genetic linkage map in man using restriction fragment length polymorphisms. American Journal of Human Genetics, Houston, v. 32, n. 3, p. 314-331, 1980.

BURNNET, A. A 'saga' político-ecológica da algaroba no semiárido brasileiro. Journal of Social Studies, Erzurum, v. 19, n. 38, p. 148 175, 2017.

COSTA, D. F.; VIEIRA, F. A.; FAJARDO, C. G.; CHAGAS, K. P. T. Diversidade genética e seleção de iniciadores ISSR em uma população natural de mangaba (Hancornia speciosa Gomes) (Apocinaceae). Revista Brasileira de Fruticultura, Jaboticabal, v. 37, n. 4, p. 970-976, 2015.

CRUZ, C. D.; FERREIRA, F. M.; PESSONI, L. A. Biometria aplicada ao estudo da diversidade genética. Viçosa: Suprema, 2011. $620 \mathrm{p}$ 
CUNHA, L. H.; SILVA, R. A. G. A trajetória da algaroba no semiárido nordestino: dilemas políticos e científicos. Raízes, Campina Grande, v. 32, n. 1, p. 1-24, 2012.

DUARTE, M. C.; SANTOS, J. B.; MELO, L. C. Comparison of similarity coefficients based on RAPD markers in the common bean. Genetics and Molecular Biology, Ribeirão Preto, v. 22, n. 3, p. 427-432, 1999.

HARTL, D. L.; CLARK, A. G. Princípios de Genética de Populações. 4. ed. Porto Alegre: Artmed, 2010. 660 p.

HONGYU, K.; SANDANIELO, V. L. M.; OLIVEIRA JUNIOR, G. J. Análise de Componentes Principais: resumo teórico, aplicação e interpretação. Engineering and Science, Cuiabá, v. 5, n. 1, p. 83-90, 2015.

JACCARD, P. Nouvelles recherches sur la distribution florale. De la Societé Vaudoise des Sciences Natureles, Zurich, v. 44, n. 1, p. 223-270, 1908.

JONES, J.; DANGL, J. The plant immune system. Nature, London, v. 444, n. 1, p. 323-329, 2006.

MEDEIROS, M. A.; RIET-CORREA, F.; PESSOA, A. F. A.; PESSOA, C. R. M.; BATISTA, J. A. B.; DANTAS, A. F. M.; MIRANDA NETO, E.; MEDEIROS, R. M. T. Utilização de vagens de Prosopis juliflora na alimentação de bovinos e equinos. Pesquisa Veterinária Brasileira, Seropédica, v. 32, n. 10, p. 101410162, 2012.

MEYER, A. S. Comparação de coeficientes de similaridade usados em análises de agrupamento com dados demarcadores moleculares dominantes. 2002. 106 f. Dissertação (Mestrado em Agronomia) - Escola Superior de Agricultura Luiz de Queiroz, Piracicaba. 2002.

NEI, M. Estimation of average heterozygosity and genetic distance from a small number of individuals. Genetics, Pittsburgh, v. 89, n. 3, p. 583-590, 1978 .

PEGADO, C. M. A.; ANDRADE, L. A.; FÉLIX, L. P.; PEREIRA, I. M. Efeitos da invasão biológica de algarroba Prosopis juliflora (Sw.) DC. sobre a composição e a estrutura do estrato arbustivoarbóreo da caatinga no município de Monteiro, PB, Brasil. Acta Botanica Brasilica, Belo Horizonte, v. 20, n. 4, p. 887-898, 2006.
PIRES, I. E.; KAGEYAMA, P. Y. Caracterização da base genética de uma população de algaroba - Prosopis Juliflora (Sw.) DC. existente na região de Soledade-PB. Instituto de Pesquisas e Estudos Florestais, Piracicaba, v. 30, n. 1, p. 29-36, 1985.

REDDY, P.; SARLA, N.; SIDDIQ, E. A. Inter simple sequence repeat (ISSR) polymorphism and its application in plant breeding. Euphytica, Amsterdam, v. 128, n. 1, p. 9-17, 2002.

RODRIGUES, L. C.; SILVA, A. A.; SILVA, R. B.; OLIVEIRA, A. F. M.; ANDRADE, L. H. C. Conhecimento e uso da carnaúba e da algaroba em comunidades do Sertão do Rio Grande do Norte, Nordeste do Brasil. Revista Árvore, Viçosa, v. 37, n. 3, p. 451-457, 2013.

ROHLF, F. J. NTSYS-pc: numerical taxonomy and multivariate analysis system, version 2.1. New York: Exeter Software, 2000. $98 \mathrm{p}$.

SEKHWAL, M. K.; PINGCHUAN, L.; LAM, I.; WANG, X.; CLOUTIER, S.; YOU, F. M. Disease Resistance Gene Analogs (RGAs) in plants. International Journal of Molecular Sciences, Basel, v. 16, n. 8, p. 19248-19290, 2015.

SNEATH, P. H.; SOKAL, R. R. Numerical taxonomy: the principles and practice of numerical classification. 1. ed. W. H. San Francisco: Freeman, 1973. 573 p.

SOKAL, R. R.; ROHLF, F. J. The comparison of dendograms by objective methods. Taxon, Vienna, v. 11, n. 1, p. 30-40. 1962.

SUNNUCKS, P.; HALES, D. F. Numerous transposed sequences of mitochondrial cytochrome oxidase I-II in aphids of the genus Sitobion (Hemiptera:Aphididae). Molecular Biology and Evolution, Oxford, v. 13, n. 3, p. 510-524, 1996.

ZOLET, A. C. T.; TURCHETTO, C.; ZANELLA, C. M.; PASSAIA, G. Marcadores moleculares na era genômica: metodologias e aplicações. Ribeirão Preto: Sociedade Brasileira de Genética, 2017. $181 \mathrm{p}$. 